\title{
Prevalence of retinopathy at diagnosis among type 2 diabetic patients attending a diabetic centre in south India
}

\author{
Mohan Rema, Raj Deepa, Viswanathan Mohan
}

\begin{abstract}
Aim-To assess the prevalence of retinopathy in newly diagnosed south Indian type 2 diabetic patients attending a diabetic centre.

Methods-448 consecutive newly diagnosed type 2 diabetic patients were recruited. Four field retinal colour photography was performed and graded using a modified form of the Early Treatment Diabetic Retinopathy Study grading system.

Results-Of the 438 patients with assessable photographs, $32(7.3 \%, 95 \%$ confidence interval 5.0 to 10.2 ) had retinopathy. None of the variables tested showed a significant association with retinopathy on univariate or multivariate logistic regression analysis.

Conclusion-The overall prevalence of retinopathy at diagnosis among clinic based south Indian patients with type 2 diabetes appears to be lower than that reported among Europeans.

(Br f Ophthalmol 2000;84:1058-1060)
\end{abstract}

Diabetic retinopathy is one of the leading causes of blindness in the western world but its frequency varies in different ethnic groups. ${ }^{1-7}$ As the prevalence of diabetes is high among Asian Indians, ${ }^{89}$ studies on diabetic complications are of considerable clinical significance. We report on the prevalence of diabetic retinopathy in newly diagnosed south Indian type 2 diabetic patients.

\section{Patients and methods}

The study group comprised 448 consecutive newly diagnosed type 2 diabetic patients attending the MV Diabetes Specialities Centre at Chennai (formerly Madras) in southern India. This centre provides treatment to approximately $15 \%$ of the diabetic population of Chennai. About $95 \%$ of patients seen at the centre are drawn from southern India (Tamil Nadu, Andhrapradesh, Karnataka, and Kerala). An ongoing epidemiological study has shown that the clinical profile of the patients seen at the centre is fairly representative of the diabetic population of Chennai. ${ }^{10}$ Type 2 diabetes mellitus was diagnosed using the criteria of the WHO study group on diabetes. ${ }^{11}$ Clinical examination included recording of height, weight, and calculation of body mass index (BMI). The blood pressure was recorded in the right arm while seated.
Best corrected Snellen's acuity was recorded and analysis performed using the Snellen's reciprocal. ${ }^{12}$ Slit lamp examination was performed to document any abnormality in the anterior segment. Intraocular pressure was measured using a Schiotz tonometer before dilating the pupils. There was, however, no contraindication for dilatation in any patient.

Retinopathy was assessed after adequate mydriasis by colour photography. Four field colour photography of the retina was taken of both eyes using a 50VT Topcon retinal camera using $35 \mathrm{~mm}$ colour transparencies. The four fields taken were stereoscopic pictures of the macula, superior temporal, nasal, and inferior temporal quadrants. ${ }^{13}$ Four fields were chosen to reduce the costs and to improve compliance. The nasal field centred on the nasal margin of the disc to assess the disc, superior and inferior nasal fields in one photograph. Photographs were coded and assessed in a masked manner for the presence and severity of retinopathy and quality of photographs. The photographs were graded twice by the same observer 4 weeks apart and the mean of the two readings was taken. A modified version of the Early Treatment Diabetic Retinopathy Study (ETDRS) grading system ${ }^{14-16}$ was used to grade the photographs. A simplified description of the retinopathy levels allocated is shown in Table 1 .

The biochemical parameters (plasma glucose, serum cholesterol, and serum triglycerides) were measured using commercial kits (Boehringer Mannheim, Germany) on Ciba Corning Express Plus Autoanalyser (Medfield, USA). Glycosylated haemoglobin $\left(\mathrm{HbA}_{1 \mathrm{c}}\right)$ was measured using a machine Variant (Bio Rad, Hercules, CA, USA). Proteinuria was estimated by the sulphosalicylic acid method. ${ }^{17}$

Table 1 Levels of retinopathy

\begin{tabular}{ll}
\hline Level & Definition \\
\hline 10 & $\begin{array}{l}\text { No retinopathy } \\
20\end{array}$ \\
30 & $\begin{array}{l}\text { Microaneurysms + minimal haemorrhages and } \\
\text { cotton wool spots } \\
\text { Microaneurysms, haemorrhages, cotton wool } \\
\text { spots, and/or venous changes in one quadrant } \\
\text { and/or intraretinal microvascular abnormalities } \\
\text { and/or hard exudates }\end{array}$ \\
& $\begin{array}{l}\text { Microaneurysms, haemorrhages more than } \\
\text { level 40 + venous changes in two or more }\end{array}$ \\
& $\begin{array}{l}\text { quadrants and/or intraretinal microvascular } \\
\text { abnormalities and/or cotton wool spots }\end{array}$ \\
& $\begin{array}{l}\text { Severe preproliferative retinopathy with venous } \\
\text { beading, intraretinal microvascular } \\
\text { abnormalities and numerous cotton wool spots }\end{array}$ \\
& $\begin{array}{l}\text { Proliferative retinopathy } \\
\text { Proliferative retinopathy and high risk } \\
\text { characteristics }\end{array}$ \\
&
\end{tabular}


Table 2 Prevalence of retinopathy by photographic assessment

\begin{tabular}{lrr}
\hline Retinopathy level & No $(n=438)$ & $\%$ \\
\hline 10 & 406 & 92.7 \\
20 & 23 & 5.3 \\
30 & 4 & 0.9 \\
$31-50$ & 4 & 0.9 \\
$\geqslant 60$ & 1 & 0.2
\end{tabular}

Statistical analysis was carried out using the SPSSC package (version 4.0.1, Chicago). Student's $t$ tests, $\chi^{2}$ tests, or Fisher's exact tests were employed as appropriate. Univariate and multiple logistic regression analyses were carried out using retinopathy as the dependent variable and age, body mass index, systolic BP, diastolic BP, glycosylated haemoglobin, serum cholesterol, triglycerides, and smoking as independent variables.

\section{Results}

The study population consisted of 448 patients with a mean age of 48 (SD 14) years; $69 \%$ of the patients were men with a mean age of 46 (12) years and BMI 24.1 (3.5) $\mathrm{kg} / \mathrm{m}^{2}$ while the women were of mean age 47 (17) years with BMI $26.2(5.0) \mathrm{kg} / \mathrm{m}^{2}$.

Of the 448 patients photographed the photographs were of good quality in 398 $(88.8 \%)$, in 40 patients $(8.9 \%)$ they were satisfactory, and in three $(0.7 \%)$ they were unreadable. In seven patients the photographs could not be taken for various reasons: camera failure $(\mathrm{n}=2)$, mature cataract $(\mathrm{n}=2)$, or inability to cooperate $(n=3)$. Of the 438 patients with assessable photographs, the photographs of both eyes could be graded in 430 patients $(98.2 \%) ; 1.1 \%$ of the nasal photographs, $0.9 \%$ of the superior temporal photographs, and $0.9 \%$ of the inferior temporal photographs could not be graded. In these patients grading was based on the remaining fields.

Table 2 presents the prevalence of retinopathy. Overall, 32 patients $(7.3 \%, 95 \%$ confidence interval (CI) 5.0 to 10.2 ) had diabetic retinopathy. One patient with retinopathy and 28 patients without retinopathy had reduced vision mainly from non-diabetic causes such as cataract or central retinal vein occlusion. The two patients with mature cataract subsequently underwent cataract extraction and neither had diabetic retinopathy.

The subjects with retinopathy had a lower BMI (mean $23.7 \mathrm{~kg} / \mathrm{m}^{2}, 95 \%$ CI 23.7 to 24.7 ) than the non-retinopathy group (mean $25.0 \mathrm{~kg} / \mathrm{m}^{2}, 95 \%$ CI 24.6 to 25.5 ), $\mathrm{p}=0.031$. There was no significant difference between any of the other clinical or biochemical parameters in those with and those without retinopathy.

None of the variables studied was found to be associated with diabetic retinopathy either on univariate or multiple logistic regression analysis.

\section{Discussion}

In Europeans the prevalence of retinopathy at the time of diagnosis of type 2 diabetes varies $^{18-24}$ and in the United Kingdom Prospective Diabetes Study (UKPDS) 35\% of type 2 diabetic subjects were reported to have retinopathy at diagnosis. ${ }^{23}$ This is considerably higher than that seen in our study $(7.3 \%)$ and another from the same city but without retinal photography $(6.9 \%) .{ }^{24}$ It therefore appears that the prevalence of retinopathy at the time of diagnosis of diabetes in our patients is lower than that reported in the $\mathrm{UK}^{23}$ and in the USA $^{181921}$ but is similar to that reported from Australia. ${ }^{18}$ One possible explanation is that there could be a longer period of undiagnosed (asymptomatic) type 2 diabetes in the UK. The mean age of the patients at the time of diagnosis in our study was considerably lower (men 45 (12) years, women 48 (12) years) than in the UKPDS study (men 52.4 (9) years, women 53.5 (8.8) years). ${ }^{23}$ Another explanation could be that the time at which patients seek medical attention may vary between India and the UK as a result of the different health systems.

The limitations of this study are that it is clinic based and the sample size is small. Although referral bias cannot be excluded, this is unlikely to affect our results significantly because the patient profile at our centre is similar to that in an ongoing epidemiological study. ${ }^{10}$ The strength of this study is that it is based on retinal photography and standard grading techniques and, indeed, is one of the first studies of retinopathy using these techniques in south Asia.

In conclusion, using retinal photography we have found that the prevalence of diabetic retinopathy at diagnosis of diabetes in this south Indian clinic based study is $7.3 \%$ which appears to be lower than that reported in European subjects.

The authors thank Mr Prem for the retinal photography, Mr A $\mathrm{K}$ Mathai for statistical help, and Mrs G Malarvizhi for secretarial help in typing the manuscript.

1 Klien R, Klein BE, Moss SE. Visual impairment in diabetes. Ophthalmology 1984;91:1-9.

2 Vision problems in the United States. Data analysis: definitions, data sources, detailed data tables, analysis, interpretation. New York: National Society to Prevent Blindness, 1989:1-46.

3 Caird FI, Pirie E, Ramsell TG. The natural history of diabetic retinopathy. In: Diabetes and the eye. Oxford: Blackwells, 1968:72-100.

4 Dorf E, Ballantyne EF, Bennett PH, et al. Retinopathy in Pima Indians. Relationships to glucose level, duration of diabetes, age at diagnosis of diabetes and age at examination in a population with a high prevalence of diabetes mellitus. Diabetes 1976;25:554-60.

5 Ballard DJ, Melton LJ, Dwyer MS, et al. Risk factors for diabetic retinopathy: a population based study in Rochester, Minnesota. Diabetes Care 1986;9:334-42.

6 Rema M, Ponnaiya M, Mohan V. Prevalence of retinopathy in non insulin dependent diabetes mellitus at a diabetes centre in southern India. Diabetes Res Clin Pract 1996;34: 29-36.

7 Dandona L, Dandona R, Naduvilath, TJ, et al. Population based assessment of diabetic retinopathy in an urban population in southern India. Br f Ophthalmol 1999;83:937-40.

8 Ramachandran A, Jali MV, Mohan V, et al. High prevalence of diabetes in an urban population in south India. BMF 1988;297:587-90

9 King H, Auberti RE, Herman WH. Global burden of diabetes, 1995-2025: prevalence, numerical estimates and projections. Diabetes Care 1998;21:1414-31.

10 Mohan V, Ravikumar RK, Shanthi Rani CS, et al. Intimal medial thickness of the carotid artery in South Indian diabetic and non-diabetic subjects: the Chennai Urban Population Study (CUPS). Diabetologia 2000;43:494-9.

11 World Health Organization. Diabetes mellitus. Report of a WHO study group. Technical Report Series No 727. Geneva: WHO, 1985.

12 Ferris FL, Kassoff A, Bresnick GH, et al. New visual acuity charts for clinical research. Am f Ophthalmol 1982;94:91-6.

13 Moss SE, Meuer SM, Klein R, et al. Are seven standard photographic fields necessary for classification of diabetic photographic fields necessary for classification of diab
retinopathy? Invest Ophthalmol Vis Sci 1989;30:823-8.

14 Classification of diabetic retinopathy: detailed grading of stereo-color photographs. In: Early treatment of diabetic 
retinopathy study manual of operations. Baltimore, $\mathrm{MD}$ : Early Treatment of Diabetic Retinopathy Study Coordinating Centre, Department of Epidemiology and

15 Early Treatment of Diabetic Retinopathy Study Research Group. Grading diabetic retinopathy from stereoscopic colour fundus photographs: an extension of the modified Airlie House classification. ETDRS Report. Ophthalmology 1991;98:786-806.

16 Klein BEK, Davis MD, Segal P, et al. Assessment of severity and progression of diabetic retinopathy. Ophthalmology 1984;91:10-17.

17 Varley H, Gowenlock AH, Bell M. Practical clinical biochemistry. London: Heinmann, 1980:600-1.

18 Harris MI, Klein R, Welborn TA, et al. Onset of NIDDM occurs at least 4-7 years before clinical diagnosis. Diabetes Care 1992;15:815-9.

19 Klein R, Klein BEK, Moss SE, et al. The Wisconsin Epidemiologic study of Diabetic Retinopathy. III. Prevalence and risk of diabetic retinopathy when age at diagnosis is 30 or more years. Arch Ophthalmol 1984;102:527-32.
20 Owens DR, Volund E, Jones D, et al. Retinopathy in newly presenting non insulin dependent (type 2) diabetic patients. Diabetes Res Clin Pract 1988;9:59-65.

21 Klein R, Klein BEK, Moss SE, et al. The Beaver Dam study: retinopathy in adults with newly discovered and previously diagnosed diabetes mellitus. Ophthalmology 1992;99:5862.

2 Nagi DK, Pettitt DJ, Bennett PH, et al. Diabetic retinopathy assessed by fundus photography in Pima Indians with assessed by fundus photography in Pima Indians with 1997;14:449-56.

23 Kohner EM, Aldington SJ, Stratton IM, et al. Diabetic retinopathy at diagnosis of non insulin dependent diabetes mellitus and associated risk factors. United Kingdom Prospective Diabetes Study 30. Arch Ophthalmol 1998;116: 297-303.

24 Ramachandran A, Snehalatha C, Vijay V, et al. Diabetic retinopathy at the time of diagnosis of NIDDM in South Indian subjects. Diabetes Res Clin Pract 1996;32: South 